\title{
Tracking Saudi EFL Students' Reflections of Online Learning During Coronavirus: Different Rounds
}

\author{
Ahmed Al Shlowiy * \\ English Language and Preparatory Year Institute, Royal Commission for Jubail, Al-Jubail, Saudi Arabia
}

\section{OPEN ACCESS}

Edited by:

Sreekanth Kumar Mallineni,

Majmaah University, Saudi Arabia

Reviewed by:

Bijaya Kumar Padhi,

Post Graduate Institute of Medical Education and Research (PGIMER),

India

Nicos Souleles,

Cyprus University of Technology,

Cyprus

*Correspondence:

Ahmed Al Shlowiy

shlowiy_a@jic.edu.sa

Specialty section:

This article was submitted to

Digital Learning Innovations,

a section of the journal

Frontiers in Education

Received: 28 September 2021 Accepted: 04 November 2021

Published: 20 December 2021

Citation:

Al Shlowiy A (2021) Tracking Saudi EFL Students' Reflections of Online Learning During Coronavirus: Different Rounds.

Front. Educ. 6:770786.

doi: 10.3389/feduc.2021.770786
The sudden shift into online learning due to COVID-19 has produced many challenges and new educational approaches across all educational systems. Language learning systems were enforced to utilize fully remote education solutions. Responding to COVID-19 is a crucial investigation to find out the challenges, barriers, suggestions, concerns, and deficiencies of teaching English in Saudi Arabia. It also assists in developing the Saudi English as a Foreign Language (EFL) context in the future and support its students, teachers, and policymakers. This study tracks the influence of this shift on the EFL students in a Saudi high school. Data collection depends on reflective questions sent to the students through the survey and WhatsApp Group three times during the pandemic: April 2020, October 2020, and April 2021. The results show that students faced several threats, ambiguities, and deficiencies that are classified into: (a) students' emotions, (b) learning environment, (c) student characteristics, and (d) deficiencies and needs. The students gradually acquired experience to deal with those issues and cope with their frustration. Then, they performed in either positive or negative ways depending on their acceptance of the online learning context. The study ends with some implications to efficiently use different virtual tools in the EFL context.

Keywords: coronavirus, emergency remote teaching, online learning, Saudi EFL context, students' acceptance, post-COVID education

\section{INTRODUCTION}

Coronavirus has had a great impact on education across the world. Its threat has presented many challenges for educational systems in most countries. It is the first time to compel all educational organizations across the globe into online learning (Williamson et al., 2020). To control its transmission, the Saudi government suspended all schools and universities starting on March 9, 2020. It shifted all educational activities to the distance learning system during the Coronavirus pandemic. This is a common practice to move into online education in times of distractions, or natural disasters (Swartz et al., 2018). However, such a rapid shift had affected the quality of the online educational process and confused the entire society for several months (Al Shlowiy et al., 2021).

Most people did not know what to do, how to perform their tasks, and whom they follow. Students were not excluded. They questioned their online duties, learning procedures, assessment policies, and attending measures. They were rapidly moved to online education without well-prepared learning experiences. They were concerned about the types of hardware and software. For more than 2 weeks, confusions, puzzles, and rumors controlled the educational debates across the country. In the beginning, teachers and students had nothing to do except waiting for decisions and instructions of 
the policymakers. Then, they started building their knowledge, experience, awareness, reflection, and behavior across the long period of COVID-19. The pandemic has lasted for more than 20 months when this paper was written.

This current sudden shift created new instructional approaches to deliver the lessons. Many educational institutions were enforced to continue teaching by fully remote education solutions. This also led to new terminologies, such as emergency remote teaching (ERT) (Hodges et al., 2020), to show this type of emergency distance teaching. Using such terminology enables the researchers to distinguish between a crisis-situation online learning and regular online learning.

The purpose of this study is to track the influence of the emergency shift to remote education due to the outbreak of Coronavirus on the students of English as a Foreign Language (EFL) in Saudi Arabia. It intended to study their reflections in three different times across the pandemic: April 2020, October 2020, and April 2021. It compares their reflections in these periods to figure out the changes in students' acceptance, progress, and recognition. Also, it discusses students' experiences, concerns, and perceptions of the remote educational alternatives. This study can assist in understanding their difficulties, challenges, mistakes, and needs. The researcher aimed to investigate the ability and readiness of students to use the online platforms and resources during this period. Also, this study enriches the literature by documenting valuable details about this long-lasting shift by answering the following questions:

1. How did the shift to distance learning affect EFL students during COVID-19?

2. What have they learned throughout this long period of the school closure?

\section{RELATED LITERATURE}

Literature includes many studies about regular online education courses that last for a specific time such as a semester or a few weeks (Mutambik, 2018; Oyaid \& Alshaya, 2019; Sharma, 2019; Alshehri \& Cumming, 2020; Kite et al., 2020), but not for a long time. These studies also discuss well-designed courses that are developed and taught for years. On the other hand, studies about ERT are still growing because it is the first time in history to have a long emergency shift to distance learning. Moreover, some recent studies about ERT showed that most courses and plans were not well developed (Hakami, 2020; Johnson et al., 2020; Al Shlowiy et al., 2021). Therefore, this study attempted to fill in the gap by focusing on the acceptance and perceptions of ERT for a long time that includes three semesters.

Online learning is known by many terms including e-learning, virtual learning, internet-enhanced learning, and distance learning (Moore et al., 2011). It is delivered through different learning platforms that are described by learning management systems (LMS), such as Blackboard, Moodle, WebCT, and Canvas. These platforms provide virtual learning environments relying on technology-mediated methods for communication without any physical interaction
(Moore et al., 2011). They allow teachers and students to share information, collaborate, and design meaningful learning activities (Lonn \& Teasley, 2009).

Well-designed online learning activities can produce useful interaction to satisfy the learning experience and meet students' expectations. These activities support modern teaching approaches, autonomous learning, flexible learning, and collaborative learning (Baytiyeh, 2019; Al Shlowiy \& Layali, 2020). Moreover, learning materials are widely presented in LMS and available at all times for students to learn at their suitability.

In Saudi educational institutions, Mutambik (2018), Alshehri et al. (2019), Oyaid and Alshaya (2019), Sharma (2019), and Al Shlowiy and Layali (2020) display that students have positive perceptions of e-learning systems, the usability of its features, high-quality of the learning materials, interactive learning settings, and its friendly interface. Although LMS provides a simple navigation process, independence, and flexibility in many educational institutions for several years, its general usage is insignificant and has not met the advisable usage level (Bousbahi \& Alrazgan, 2015).

Although there are benefits of online learning systems, research shows some issues, such as the issues of internet connection (Alshehri \& Cumming, 2020), personal devices issues (Hakami, 2020), students' privacy issues (Sharma, 2019), screen issues (Oyaid \& Alshaya, 2019), and technical issues (Al Shlowiy et al., 2021). Moreover, some teachers have negative perceptions of using online learning so that they do not effectively employ its methods in their teaching experiences. They are not comfortable or prepared to teach online. Teachers of an older age resist accepting online teaching in their instructions while some teachers use online learning only for the sake of using technology (Yuan \& Kim, 2014) by providing basic educational purposes, such as submitting assignments, sharing files, making announcements, and posting grades (Al Shlowiy \& Layali, 2020). A few teachers adapt their face-to-face teaching approaches to fit the online environment without adopting different online-based teaching approaches (Zanjani et al., 2016).

On the other hand, students have different perceptions of using online learning depending on their teachers' utilization of LMS (Bousbahi \& Alrazgan, 2015). Although they enjoy the convenience of the online learning system, they generally prefer the face-to-face learning environments more than the online learning environments (Al Shlowiy et al., 2021), especially if they cannot exchange ideas, boost their skills, and increase their knowledge. In some online learning environments, students only perform the minimum requirement for achieving the scores (Kite et al., 2020) because the online platforms are used as a digital syllabus or as storage places for digital resources (Yuen et al., 2009). Therefore, such administrative uses of online learning do not accomplish the pedagogical objectives of learning and create a negative attitude towards it among students.

\section{Online Learning Within a Disaster}

Crisis-situation online learning differs from a well-prepared online learning. Shifting to online learning due to main 
emergencies, such as natural disasters, epidemics, earthquakes, and hurricanes can harshly disrupt formal education. Research documents several examples:the 2010 floods in Pakistan, the 2011 Typhoon Washi in the Philippines, the 2017 South Asia floods, and the 2017 Hurricanes Harvey and Irma in the United States as well as in the case of outbreaks, such as swine influenza in 2009 and Ebola in 2013 (Swartz et al., 2018; Baytiyeh, 2019). During these crises, schools were temporarily closed or destroyed for several days or weeks. Also, millions of students were prevented from attending their schools and communicating with their teachers.

Moving education into online learning as a response to any regional disaster is a common practice (Swartz et al., 2018). Nevertheless, COVID-19 was different in disturbing most educational institutions across the world (Johnson et al., 2020). It was also different in its length as it has been lasting for more than 20 months at the time of writing this paper without a certainty of its future. While many studies focus on the benefits and positive uses of distance learning during the crisis, literature has few publications about its negative effects on educational, social, economic, and political life worldwide (Johnson et al., 2020). It is still a fresh pandemic that has not been studied enough and is still threatening the world with many anxieties for students, teachers, and institutes on their abilities to maintain education in a safe and healthy environment. Studies about COVID-19 exist in literature but many of them focus on a short period of the pandemic while this study attempted to track it for a longer time.

EFL context. Online learning for EFL context and how it responded to COVID-19 is an essential investigation to find out the challenges, barriers, and suggestions. This investigation can reveal different deficiencies of online learning and what we need to develop in the future, as well as how to support students, teachers, parents, and policymakers (Watermeyer et al., 2020). Such a pandemic can illustrate the reality of the efforts to support online learning activities for EFL students and enable them to practice the language on online platforms. In addition, this study examines the reflections of some Saudi EFL students on using the different virtual tools and how they accepted the first unexpected shift to ERT in their education.

\section{Theoretical Framework}

This paper intends to track Saudi EFL students' reflections of shift into ERT responding to COVID-19. It investigates their perceptions of using online learning and acceptance of this emergency shift and its influences. To achieve this goal, Technology Acceptance Model (TAM) and the theory of TaskTechnology Fit (TTF) are used to examine the reflections, perceptions, and acceptance of shifting into ERT. Applying both models as a framework on EFL students' reflection and acceptance of online learning during the pandemic is rarely used in literature.

TAM was theorized by Davis (1989) to use and predict the perception, acceptance, and adoption of technology. It is empirically validated and well-established to function with remarkably high quality (Shih \& Chen, 2013). It consists of two main factors. The first one is Perceived Usefulness (PU), which is "the degree to which a person believes that using a particular system would enhance his or her job performance" (Davis 1989, p. 320). This factor can explain the users' intention to accept and use technology. The second one is Perceived Ease of Use (PEOU), which is "the degree to which a person believes that using a particular system would be free of efforts" (Davis 1989, p. 320). This factor focuses on explaining the users' acceptance and usage of technology in TAM. Moreover, it is a flexible model that can include various external variables and dependent variables, such as environment, culture, and various features within worldwide technologies (Chuttur, 2009).

The theory of TTF was theorized by Goodhue and Thompson (1995) to evaluate the role of technology in performing a specific task. It is defined as "the degree to which a technology assists an individual in performing his or her portfolio of task" (p. 216). This theory proposes that users are more likely to adopt any technology when it improves their performance in accomplishing the tasks at hand. It supposes that technology should have a positive impact on individual performance and be used if its abilities match the tasks that the user must perform. Goodhue and Thompson (1995) included eight factors: quality, locatability, authorization, compatibility, training and ease of use, production timeliness, systems reliability, and relationship with users. TTF can also predict the user's performance and effectiveness of any technology under investigation.

This study applies TAM and TTF to track the difficulties that affect the acceptance, adoption, and use of ERT in the Saudi EFL context due to COVID-19. TAM is one of the most dominant and regularly used models to study technology adoption and users' evaluation of the technology based on a task at hand (Shih \& Chen, 2013), which is the distance learning in this study. TAM was criticized by some as an oversimplified model that might not provide reliable framework to describe the user's decisions, reflections, and behaviors to technologies as well as the absorption of them (Bagozzi, 2007). Therefore, TTF is used to enhance TAM by assuming that users choose the technology that enables them to complete specific tasks (Wu \& Chen, 2017). Combining both models can lead to better prediction of technology adoption (Shih \& Chen, 2013; Wu \& Chen, 2017). In this study, both models are combined to describe the acceptance of online learning technologies by gaining valuable insights into how individuals experienced this situation. They are employed to track the influence of ERT on EFL students' acceptance, attitude, intention, and adoption and to identify the challenges that students face.

\section{RESEARCH DESIGN AND CONTEXT}

This study involved the descriptive approach about the case of school suspension in Saudi Arabia due to the pandemic of coronavirus. This specific case of school lockdown lasted a long time and recounted many problems in which participants could learn from its difficulties and ambiguities (Merriam, 2009). This case study focused on understanding 
TABLE 1 | The questions and responses of the first reflective round on April 2020.

Question

Arabic responses

\section{4}

232

269

217
English responses



11

14

10

How can you continue your learning in this situation of ERT?

TABLE 2 | The questions and responses of the second reflective round on October 2020

Question

How did you find ERT so far?

What are the best practices of online learning?

Which practice is the best to study and teach from home?

What are the disadvantages of ERT?

What suggestions do you have?
Arabic responses

English responses

124

109

114

98

119
12

8

8

9

10

TABLE 3 | The questions and responses of the third reflective round on April 2021.

Question

How did you find ERT so far?

What are the differences between online learning in April 2020 and April 2021?

How can we succeed in online learning? What do we need?

What are the disadvantages of online learning?

What have you learned through online learning during COVID-19?

What suggestions do you have?
Arabic response

$\begin{array}{cc}88 & 9 \\ 94 & 11 \\ 68 & 10 \\ 73 & 10 \\ 63 & 8 \\ 48 & 9 \\ & \\ \end{array}$

students' reflections, perceptions, and acceptance of online education during ERT.

The study targeted the EFL students in a secondary school in Saudi Arabia. After obtaining the required approval, all participants were individually informed about the study requirements, signed the consent form, and expressed their interest in joining. They were provided with some open-ended questions (Tables 1, 2, 3) to enable them to reflect on their experience of any confusion, difficulty, concern, and delay caused by this case of the school lockdown. Their reflections were collected at three different times: 1) within the first month of the lockdown in Saudi Arabia (April 2020), 2) after 7 months that was at the beginning of the academic year 2020-2021 (October 2020), and 3) after 13 months that was before the end of the academic year 2020-2021 (April 2021).

The researcher tracked the reflections, complaints, concerns, and difficulties they voiced about school suspension and other related official decisions of language learning during the COVID19 pandemic. Such reflections can show their acceptance of the shift into distance learning, use of online learning approaches, and adaption of ERT.

After obtaining the required approval from one of the secondary schools, the researcher invited all EFL students through their teachers of English. At the first reflection time, the questions were sent to the EFL students at the beginning of April 2020. There were 422 students in 12 EFL classes with an average number of 35 students in each class. They attended the second and third years of secondary school, with the age range of
16-18 years. After 2 weeks there were 289participants, which was $68.5 \%$ of students. Table 1 shows the questions and responses of this round.

At the beginning of the new academic year 2020-2021, the researcher created a special WhatsApp Group to track the reflections of those students. He sent an electronic invitation to the students in the third year throughout the school platform. The invitation was sent to six classes with about 200 students. It was sent to precisely track those students who were in the second year when they participated in April 2020. Other students who were in the third year graduated in May 2020. The invitation was introduced by a bilingual description of the objectives of the group. It was sent at the beginning of September 2020 with two following reminders.

By the end of September 2020, the group had 143 students. The researcher ensured that they understood the research process. He shared his contact information and social media accounts with them. They were motivated to share their experiences after they recognized that the researcher did not belong to their school. To start the second round of questions, the researcher followed a special strategy in delivering the questions. $\mathrm{He}$ announced a question in the WhatsApp group and waited $48 \mathrm{~h}$ for responses before announcing the next question. There were five questions written in Arabic and English. The students had the option to write or say the answer in any language. Students were allowed to comment on any answer. Some students left the group within the discussion. Table 2 shows the questions and the number of responses to each one. 
TABLE 4 | The emergent concerns and indicative examples from each reflective round.

\begin{tabular}{|c|c|c|c|}
\hline Concern & Round one & Round two & Round three \\
\hline Fair & dark future & - & - \\
\hline Failure & low GPA, not passing & - & - \\
\hline Haziness & devices and access & - & - \\
\hline Resistance & home environment & - & - \\
\hline Missing & Teachers' gaudiness, support & other students, physical classrooms & real communication and real exams \\
\hline Feeling & - & boring, shyness & - \\
\hline Easiness & - & accepting excuses and high marks & - \\
\hline Awareness & - & no control/power & - \\
\hline Discoveries & - & online resource & - \\
\hline Deficiency of Learning & - & - & compensation and desire to learn \\
\hline Responsibility & - & - & self-management and discipline \\
\hline Carelessness & - & - & play and cheating \\
\hline
\end{tabular}

The researcher started the final round of questions at the end of the academic year. By the beginning of April 2021, there were 92 members so that he required the school to send a new invitation to those EFL students. That invitation brought 34 students back to the group. Thus, six new questions (repeated questions and new questions) were sent to 126 students. One of the questions clearly asked about what the students learned during the pandemic. The researcher employed the same strategies as the previous time. While the majority of students participated in this round, 52 students answered all questions, especially in Arabic. Compared to the previous rounds, they did not efficiently participate as Table 3 shows.

While using WhatsApp to collect students' responses, the researcher was active daily in reminding them to answer the questions, asking for clarification, and explaining any issue. Due to the restrictions of COVID-19, the WhatsApp group works as a survey with detailed questions to collect data at different times. On several occasions, the group worked as a focused group that brought students together to discuss the topic, capture their perceptions, and document under the researcher's guidance (Merriam, 2009). WhatsApp, which is the most common free social platform among Saudis, helped students to have their voices on this research problem and express their thoughts and concerns honestly. During the crisis of COVID-19, many teachers used the group feature of WhatsApp to quickly communicate with their students.

Analyzing the data was an inductive process by examining the responses and reading them several times for understanding purposes. It was the first step of analyzing data that happened simultaneously while collecting them, as a recursive and dynamic process (Merriam, 2009). The screening process examined 2,134 responses in both languages and translated all Arabic responses into English.

About half of these responses were in the first reflective round. Microsoft Office Excel was used for coding the results into 108 codes related to the case study. Using thematic analysis 31 themes emerged from the data. These themes were categorized into 12 concerns that occurred upon the emergency shifting to online learning. Finally, the researcher ensured that each concern was reported by at least 10 students as a validity condition. Table 4 shows the resulting concerns with examples of some themes for each round.

\section{RESULTS}

The goal of this study was to investigate the EFL students' reflection of ERT during the COVID-19 pandemic as an existing case. This section describes the results based on the coded and analyzed data that were collected at three different times. Therefore, the results are classified into three categories based on the times of data collection. The first time of data collection was within the first month of school suspension in Saudi Arabia, which was in April 2020. The second time was after 7 months of school suspension, which was in October 2020. The third time was in April 2021, which was by the end of the academic year 2020-2021.

The first category shows that students were in a period of concerns, ambiguities, and deficiencies due to the sudden change. Table 4 displays the results of their responses in the first round that were coded into five main themes: Fair, Failure, Haziness, Resistance, and Missing. It is obvious that students' reflection at this time was full of frustration and disruption. It shows how hard that period was.

It is a matter of fact that students faced several challenges when they were shifted into ERT. There was a dysfunction of the education system that led to negative consequences on the learning process. They showed how they missed their physical communication in their classrooms as well as missing their teachers' support and guidance. They were afraid of losing marks and required knowledge to pass the course with a high GPA and to be ready for higher education. They were concerned about how to take the academic achievement test, Tahsseli Exam, for all high school graduates.

At their home, there was a disturbance in the daily routine. They indicated that the home environment does not provide effective learning as the classroom environment does. They were worried about the internet connection, device availability, and parent experience. In fact, they were not equal in these concerns. For example, many students suffered from the shortage of computers and required devices at their homes while a few students did not mention these issues. In addition, most students complained about the internet connections and Madrasati Platform readiness. A number of students lacked the right help from their parents and siblings. 
The second category shows the results of students' reflections of using online learning after 7 months of the shift to ERT. This category includes new concerns in addition to the repeated concerns of the previous period, such as Missing concern. Table 4 presents the coded themes of students' responses in the second reflective time. The themes are Missing, Easiness, Feeling, Awareness, and Discoveries. These themes included positive and negative results based on these mixed concerns.

The repeated concerns are related to the themes of missing and feeling. For instance, they missed each other and real classrooms as they did 6 months ago. There were some concerns about feeling bored during distance learning. Some students felt shy to participate in virtual classes. They did not feel relaxed when they talked through the active camera or in the recording sessions. However, there is a reduction in these repeated concerns compared with the previous round of the students' reflection. I mean students did not strongly suffer from these concerns as they did the first time. Also, such concerns were reported by some students in this round while the concerns of the first round were reported by most students.

Moving to the new concerns of this round of students' reflection, they result in the themes of easiness, awareness, and discoveries. This shows that some students felt comfortable at this time and started to have fun during their virtual classes. They reported that they could get high marks and submitted any excuse for their absence. They recognized that their teachers had lost their power in the virtual classrooms that offer superficial control. On the other hand, other students took care of their learning, thought about alternative learning sources, boosted their understanding, and used the dictionary to find the meaning of new vocabulary.

The third round shows the results of students' reflections of using online learning after 13 months of the shift to ERT. The results are shown in Table 4, which includes four themes for the third round: Missing, Deficiency of Learning, Responsibility, and Carelessness. This round has fewer themes than the previous rounds because it obtained fewer responses. Also, students were moved into their comfort zone without a lot of concerns. These four concerns cannot be classified into positive or negative. This means that no specific direction of concerns exists because students could be divided into two groups: responsible and non-responsible or careful and careless students.

Students neither repeated those technology-based difficulties of the previous reflective rounds nor complained about the shift into online learning during COVID-19. However, they still missed their friends, teachers, physical classrooms, and real exams. Some students repeated the easiness of the exams and had several ways to pass the course with no attention to the real learning. Moreover, it was found that the students understood the reasons for this shift into ERT. Also, they looked as if they had acquired enough experience to deal with those issues, were familiar with most of these difficulties, and recognized the reality of them.

As a different finding in this round, the students suggested some how-to practices to encounter the difficulties. Their suggestions went in positive or negative directions depending on each student's responsibility and seriousness. For positive suggestions, the findings show that students used numerous learning resources to compensate for any learning loss, started their self-management to discipline themselves, and practiced independent learning. For negative suggestions, it was found that some students developed several ways to plagiarize and cheat as well as using the class time to play games, watch videos, share links with friends.

\section{DISCUSSION}

At the time of writing this paper, the impact of COVID-19 on Saudi educational institutions has been experienced for more than 16 months. In that period, people were forced to connect virtually while they were physically distant. Such a long period required collecting data in three different times of the crisis. This helped to find various reflections and perceptions of this impact. Also, data collecting at three times enabled the researcher to build the reflective questions at every round because forming the questions was evolving process. Each round helped to form the questions of the next round. Moreover, leaving a period of time between the rounds assisted in finding progress in students' experience, perceptions, and reflections. The researcher waited more than 5 months before conducting the second round and the same time for the third one.

This section discusses the results based on the two research questions. It answers the first question in general by discussing the findings of all reflective rounds together. Then, it provides specific details for the second question by tracking the findings of each reflective round. This might help in tracking any change in students' perceptions and reflection of ERT and their acceptance of its technologies. It also shows if the EFL students could use these technologies for their future learning.

\section{The First Research Question}

The first question is: How did the shift to distance learning affect EFL students during COVID-19? This question guided the study to find students' reflections of the sudden shift to ERT due to COVID-19. It focused on their perceptions of using distance learning during the crisis and explored what difficulties they faced in this period. To answer this question, the findings are discussed through four main effects: (a) students' emotions, (b) learning environment, (c) student characteristics, and (d) deficiencies and needs.

Students' Emotions. This effect comes from students' feelings of using ERT during the pandemic, such as their feeling of losing the required knowledge, getting a low GPA, boring virtual classes, shyness in speaking to a camera, and missing friends. There is no doubt that students might receive negative influences on their emotions due to any sudden change in learning system. Also, there is a consequence on several affective factors related to students including their perceptions, self-confidence, anxiety, and enthusiasm (Dewaele et al., 2019) that will, in turn, influence their acceptance of ERT and might result in a negative reaction of using it. This is what was found by many students in this study. 
The students reflected on several threats that increased their anxiety about using ERT. They were fully confused about shifting away from the traditional class-based ways of learning. In the beginning, distance learning was a model of frustration and hesitation. Most students agreed that school suspension led them to miss each other, teachers, social life, and real communication. This feeling emphasizes the importance of the emotional aspect in language learning (Dewaele et al., 2019). These factors play an important role in language learning, lesson understanding, grade losing, and subsequently failing the course or getting a low GPA. Kebritchi et al. (2017) state that positive students' emotions and affective factors support active and meaningful learning.

Learning Environment. This effect has resulted from students' reflection about their home situation and readiness to shift to ERT as well as their parent engagement and the individual differences that existed among them. According to Kebritchi et al. (2017), these factors are among the challenges of providing effective remote learning environments. Many students did not observe the quality of the online environments due to the rapid shift to ERT. Therefore, most students preferred traditional face-to-face learning rather than virtual learning although they recognized the flexibility of online learning that could go smoothly with any commitment. Such a preference of the superiority of face-to-face education might rely on a belief that direct interaction between students and teachers is difficult in an online environment (Al Shlowiy et al., 2021).

At home, the students reported many distractors that demotivated them and increased their pressure. Some students were disappointed and not able to continue their learning due to the lack of parent assistance, device availability, and internet connection. Instead of following their lessons and working on their assignments, the students had to solve their technical issues and familiarize themselves with digital features. They mistrusted the efficiency of online teaching and its educational quality, which led to unstable learning environments (Anderson et al., 2011). Such learning environments cannot engage the students in the learning process. These disengaging environments reduce the perceived usefulness of technology and its perceived ease of use.

Student Characteristics. This effect relies on how students reacted to this new learning situation, how they described their strategies to cope with it, and what they discovered about themselves. Reacting to the rapid changes in the learning context and responding to the challenges of ERT, the study found that most students recognized the new learning situations. They also understood how their performance and preference are shaped by their personalities and learning characteristics. Therefore, the students were aware of their new roles to learn distantly after being exposed to online learning for more than a dozen months. It was a sufficient time to construct their experience, knowledge, reaction, acceptance, and behavior (Shih \& Chen, 2013; Wu \& Chen, 2017; Al Shlowiy et al., 2021).

Some students took more responsibility to learn by themselves and attempted to compensate for any lack of knowledge. They looked for alternative learning resources rather than what was uploaded by their teachers on the learning platforms. They were serious students who developed the required skills of selforganization, time-management, and discipline to learn at their convenience of time and place. On the other hand, other students did not pay attention to their needs and skills at this hard time. They were irresponsible students who relied on excuses to meet the attendance conditions or the deadlines. They also did not perform in a good way and spent the lowest efforts in the practices, assignments, and examinations. According to Kite et al. (2020) the students neither completed the learning contents nor engaged in the taught classes in this less stimulating learning environment.

Deficiencies and Needs. This effect refers to any lack in the learning process such as required devices, learning management system, internet connections, teacher's authority, feedback or guidance, and technical support. Because there is no perfect learning context, each learning situation has some deficiencies. Online learning is the same and ERT is not excluded, especially when it exists suddenly without planning (Johnson et al., 2020; Al Shlowiy et al., 2021).

The study found different individual needs and inquiries that led to extensive concerns. Many students lacked the suitable training to use the online learning platform. Similarly, there was a need to have more learning resources that support different learning styles and individual differences. Some students also required hardware devices and steady internet connections. Understanding these needs might help in fulfilling their perceived ease of use and actual ease of use of distance learning, which will support them to succeed in their learning (Yuen et al., 2009; Zanjani et al., 2016).

\section{The Second Research Question}

The second question is: What have they learned throughout this long period of the school closure? This question looked for any possible change or progress in students' reflections that might affect their acceptance of using online learning. Students play a major role in the learning process, which occurs virtually through technologies as in this study. Therefore, their reflections of the usefulness of ERT and its ease of use might matter and form students' perceptions (Al Shlowiy et al., 2021). Their perceptions might affect their performance during this period and how ERT helped them to improve their learning at home. Therefore, this question focused on students' performance and effectiveness of technologies used during the study, as Goodhue and Thompson (1995) suggest in their model of TTF.

To answer this question, the results are discussed based on the time of data collection. Data were collected in three different rounds: April 2020; October 2020; and April 2021. This means that the results are discussed below based on these three rounds.

In the first round, it was found that the learning environment was ambiguous and full of concerns. The students suffered from the sudden change without instructions or guidance. They were demotivated to study or complete their courses. They were not comfortable during this period. None of them had a clear idea about what was going on. They encountered the technical issues, support deficiencies, environmental distractions, and emotional frustrations that existed in several studies (Yuen et al., 2009; Zanjani et al., 2016; Oyaid \& Alshaya, 2019; Sharma, 2019; 
Alshehri \& Cumming, 2020; Hakami, 2020; Al Shlowiy et al., 2021)

This round could be titled with dysfunction, disturbance, interruption, or suspension based on students' responses. Their responses show that all students were mostly similar. They were classified together in one category that could be described as a negative one, such as suffering or discomfort. There is no way to divide the students' reflection into different groups at this round, as seen in the next rounds. This means that all students had mostly the same concerns, expressed the same viewpoints, and showed the same perceptions. Mutambik (2018), Oyaid and Alshaya (2019), Sharma (2019), and Al Shlowiy et al. (2021) report similar findings.

At this round of confusion, students suffered from many problems, as shown above. Their suffering indicates they did not respond in a similar or identical way to the situation. Inequality existed in their home environment, socioeconomic level, and parent engagement (Williamson et al., 2020). These factors played a central role in their acceptance of the efficiency of ERT technologies that, in turn, affected both their perceived ease and perceived usefulness. Using technologies during COVID-19 affected the performance of many students in negative ways. This goes against the theory of TTF (Goodhue \& Thompson, 1995), which assumes that technology should have a positive influence on their performance and ability to complete the task at hand.

Such a negative performance leads them to unconsciously prefer face-to-face learning when they answer the questions or reflect on their experiences. They preferred the traditional classroom although they were exposed to a complete virtual learning process for a few weeks only. Therefore, that sudden shift was not enough experiment to judge the quality of ERT as they had experienced the traditional learning for years. Indeed, they compared both learning contexts in every single activity. Such a comparison was obvious in their reflection during this round.

The second round showed that students were partly able to adapt to ERT. They overcame some difficulties and felt some comfort. They were different from the first round in dealing with the shift into online learning. For example, they were not afraid of losing marks, losing required knowledge, and passing the course with a high GPA. Some students were not concerned about being ready for higher education or how to take the academic achievement test, Tahsseli Exam, after graduating from high school.

All students understood the new situation of ERT but they differed in their reaction to it. The results show that the students reacted to ERT positively or negatively. This means that there are two different groups of students based on their perceptions. The first group shows the positive behavior of some students who accepted ERT, but they were still suffering from concentration and distraction. Their suffering was not as strong as it was in the first round because they attempted to behave differently from the first round. They were not completely passive as they were in the first round. They made some efforts to familiarize themselves with the new situation. They positively performed their online learning and reflected on given learning activities. Their perceived online learning as a new way of learning and they should adapt to it. They accepted it as a new challenge that led them to focus on how to acquire the knowledge and develop their skills, rather than to focus on passing the course or getting marks.

The second group shows the negative behavior of some students who understood the situation, but did not struggle to adapt. It looks as if they did not accept the virtual learning environment. Their reaction was not related to the learning process. They did not pay any attention to studying their courses or achieving the objectives. Instead, they used the new situation for fun and entertainment because they felt free of the teacher domination and the school administration. They chatted with their virtual classmates or played digital games during their online classes. In their opinion, online learning provided superficial knowledge without immediate effects on their lives. They also recognized the possibility to pass the course without working hard or spending efforts.

Finding different reactions of students after facing several issues of ERT and being exposed to ERT for more than 7 months enabled them to objectively compare the physical learning context with the virtual learning context. Both groups of students confirmed that the quality of ERT is not comparable to the quality of face-to-face learning. The researcher employed WhatsApp Group as a kind of collecting data to deal with "some aspect of society at a given time" (Merriam, 2009, p. 144) on a certain change. It also helped obtain more details about students' reactions and perceptions in the next round.

The third round clearly showed how students passed the hard time of ERT and moved to the comfort zone. They did not repeat the concerns of the first two rounds except the issues of missing (i.e., classmates, teachers, and school). Each participant figured out what worked for him and was able to distinguish between face-to-face learning and online learning. To most students, this round was the decision round that was built on several skills including autonomy, self-recognition, organization, timemanagement, responsibility, and judgment.

Exposing to online learning for 13 months was enough for them to judge the benefits and drawbacks of each learning environment. They were able to not only criticize different learning approaches, as they did earlier but also suggest some solutions for the problems. Also, they recommended several techniques that supported them to overcome the challenges. They became experienced students in either: (a) positive skills such as self-learning and self-management or (b) negative skills such as irresponsibility and carelessness by using fake excuses.

The first direction of skills built progressive learning depending on the acquired knowledge in 13 months of the crisis. This direction is a continuous process of the first group of students discussed in the previous round. Those students seemed to efficiently accept the online learning and coped with its difficulties, based on the TAM and TTF (Shih \& Chen, 2013; Wu \& Chen, 2017). They solved several problems, such as the learning deficiency, by using multiple learning resources or looking for suitable videos on YouTube. They attempted to compensate for their missing of social life with their teachers and students by joining WhatsApp groups for their classes, communicating privately with their teachers. They were 
accountable students who succeeded in dealing with the challenges of ERT and developing their abilities away from their teachers (He, 2020).

The second direction of skills went into a digressive process, which is an extension of the second group of students who lacked seriousness in the previous round. They did not deal with the issues. For example, missing communication with their teachers was an obvious concern since the first round but these students did not deal with this concern although other students virtually communicated with their teachers. They considered online learning as a waste of time, particularly when they found it simple to pass the course. They were experts in cheating and plagiarizing during the online assessments. They gave up early and did not benefit from their serious colleagues who passed several issues. In the end, they cared about nothing related to their learning in that unreliable teaching environment (Anderson et al., 2011).

In all three rounds, there are some constant perceptions. For example, students agreed that distance learning is not the same as face-to-face learning. They missed physical communication, social life, school environment, and official instructions. They also recognized that distance learning cannot afford compensation for these missing features although some students found alternative ways to learn and acquire knowledge as well as to virtually communicate with their teachers. However, they found no way to acquire real social life and physical communication. Moreover, students observed that their teachers had less control and their teaching role changed.

All rounds show that students had different needs according to many individual differences, such as socioeconomic levels, parental involvement, and education levels. In the first round, students were not equal in their technology readiness, awareness, and parent engagement. In the last time, students were not equal in their seriousness, self-management, and discipline. Baytiyeh (2019) states that managing inequities and student needs is important to support the continuousness of education during temporary school closures. Learning technologies could provide alternative approaches to access the educational materials, facilitate creative learning, and increase critical thinking (Baytiyeh, 2019).

\section{IMPLICATIONS}

Understanding obstacles of online learning is valuable to assist students, especially when the perceived usefulness of online learning is connected with their perceptions of it (Almarashdeh, 2016). Students' acceptance of virtual learning and adjusting to its environment depends on how well they recognize their role as independent learners ( $\mathrm{He}, 2020)$. It is difficult to improve their experience of online learning without addressing their perception that prefers face-to-face learning rather than online learning and without reducing the barriers of online learning. It is believed in Saudi Arabia that online learning is the main part of future educational plans based on the Saudi vision 2030. These plans often enable the students to perform similarly to how they do in the physical classrooms, which was reported in Cavanaugh and Jacquemin (2015) study.

Teachers may not be fully aware of the problems students faced during ERT. One of the obstacles is the technical support that may prevent learners from using and accepting online learning, particularly at the beginning. This study found that engaging students in virtual learning activities was driven by receiving expert support to enable them in overcoming technical issues (Kite et al., 2020). They spent more than 4 months understanding the technical issues and, then, reducing their concern and frustration. That means their frustration relied on their understanding of online learning (Sharma, 2019; Watermeyer et al., 2020; Alshehri \& Cumming, 2020; Al Shlowiy et al., 2021). If they understand it, they can work by themselves. Therefore, they will likely have positive perceptions of perceived ease of use and perceived usefulness toward a system that supports them to achieve the learning objectives.

It is advisable to prepare the students with a preemptive plan to smoothly shift to an online learning environment in any case of school closure (Baytiyeh, 2019). Their parents should be also trained on how effectively implement the plan for providing effective support to the students at home. The plan should simplify the ways of communication among students and interaction with the teachers. On the other hand, teachers are required to direct students through online learning materials, respond to their questions, sustain live teaching sessions, and establish suitable interaction with their students. Moreover, they play the main role to support students in how to express their emotions and show their concerns during disasters (Johnston \& Redlener, 2006). They should consider how to recognize their students' emotions and modify their instructions consequently because teachers do not have clear access to verbal and nonverbal cues.

This study shows that the official guidelines, quality expectations, academic integrity may be unclear and incomplete during this emergency shift as well as repeatedly unstable teaching environment (Anderson et al., 2011). For example, dealing with cheating and plagiarizing was one of the main challenges of educators during COVID-19 in Saudi Arabia. Al Shlowiy et al. (2021) state that students benefited from the shift to online learning to cheat in their virtual assessments and assignments. For many of them, it was the first opportunity to experience the cheating practice without being educated about its unethical use. Future plans and instructions should deal with cheating issues seriously after COVID-19.

\section{CONCLUSION}

The study reveals that Saudi students incompletely understand the practices and procedures to use online learning during the pandemic. They lack familiarity with these virtual tools and sufficient preparation to take advantage of them during school closures (Hakami, 2020; Al Shlowiy et al., 2021). Although they have accessed the technologies of ERT for a long time during the COVID-19 pandemic, they still have different issues previously reported in the literature including internet connection issues 
(Alshehri \& Cumming, 2020), personal devices issues (Hakami, 2020), students' privacy issues (Sharma, 2019), screen issues (Oyaid \& Alshaya, 2019), and technical issues (Al Shlowiy et al., 2021).

Technologies are not neutral entities that merely work well when accessing them, but they are complex with social-cultural artefacts (Williamson et al., 2020). Therefore, many students reported not only their frustration but also their annoyance when they were incapable of satisfactorily catering to their education (Watermeyer et al., 2020). ERT was a temporary solution but it could not fix social, educational, health, and digital inequalities.

The long period of the shift to online learning due to the crisis of coronavirus encourages the movement to platform-based education systems (Hillman et al., 2019). It is the first time in history entire schools across the world were forced to take their classes online (Williamson et al., 2020). Such a long time sets the ground to examine the students' achievement in online learning compared to face-to-face learning. Previous studies focused on online learning for a few weeks or a semester. COVID-19 enabled us to measure how much students learned and how much trouble they obtained compared to the previous face-to-face instruction (Williamson et al., 2020).

This study finds that the quality of education was disrupted during this period and students were not fully engaged in the learning process (Al Shlowiy et al., 2021). Although this study did not intend to discuss the benefits of using online learning or to look at the positive features, there were some positive findings of what the students have learned after 16 months, such as depending on themselves to be autonomous learners (He, 2020) and an interest in developing good skills of virtual learning (Kite et al., 2020) focusing on digital skills as they

\section{REFERENCES}

Almarashdeh, I. (2016). Sharing instructors experience of learning management system: A technology perspective of user satisfaction in distance learning course. Computers in Human Behavior 63, 249-255.

Al Shlowiy, A., Al-Hoorie, A., and Alharbi, M. (2021). Discrepancy between Language Learners' and Teachers' Concerns about Emergency Remote Teaching. Journal of Computer Assisted Learning, 37(6), 1528-1538. doi: $10.1111 /$ jcal.12543

Al Shlowiy, A., and Layali, K. (2020). Facebook and EFL Academic Writing: Students' Perspectives in a Saudi College. Sjkfu 22 (1), 40-47. doi:10.37575/h/ $\mathrm{edu} / 2325$

Alshehri, A., and Cumming, T. M. (2020). Mobile Technologies and Knowledge Management in Higher Education Institutions: Students' and Educators' Perspectives. Wje 10 (1), 12-22. doi:10.5430/wje.v10n1p12

Alshehri, A., Rutter, M., and Smith, S. (2019). Assessing the Relative Importance of an E-Learning System's Usability Design Characteristics Based on Students' Preferences. Eur. J. Educ. Res. 8 (3), 839-855. doi:10.21125/ edulearn.2019.1304

Anderson, D., Imdieke, S., and Standerford, S. (2011). Feedback Please: Studying Self in the Online Classroom. Int. J. Instruction 4 (1), 3-15.

Bagozzi, R. P. (2007). The Legacy of the Technology Acceptance Model and a Proposal for a Paradigm Shift. J. Assoc. Informamtion Syst. 8 (4), 243-254. doi:10.17705/1jais.00122

Baytiyeh, H. (2019). Mobile Learning Technologies as a Means of Maintaining Education Delivery in Crisis Situations. Int. J. Inf. Commun. Tech. Edu. 15 (3), 1-10. doi:10.4018/IJICTE.2019070101 were exposed to more digital access at home (Williamson et al., 2020).

This study sheds light on the ways to have a motivating virtual learning environment. It discussed the difficulties that make some students passive and disengaged with online materials and fellow students. Online learning systems should maintain the quality of educational courses regardless of the length of the course and whether it is delivered in normal time or in crisis time. If so, the students can accomplish the same in both situations of face-toface and online, as shown in the study of Cavanaugh and Jacquemin (2015).

\section{DATA AVAILABILITY STATEMENT}

The original contributions presented in the study are included in the article/Supplementary Material, further inquiries can be directed to the corresponding author.

\section{ETHICS STATEMENT}

The studies involving human participants were reviewed and approved by the manager of the school. Written informed consent to participate in this study was provided by the participants' legal guardian/next of kin.

\section{AUTHOR CONTRIBUTIONS}

The author confirms being the sole contributor of this work and has approved it for publication.

Bousbahi, F., and Alrazgan, M. S. (2015). Investigating IT Faculty Resistance to Learning Management System Adoption Using Latent Variables in an Acceptance Technology Model. ScientificWorldJournal 2015, 1-11. doi:10.1155/2015/375651

Cavanaugh, J., and Jacquemin, S. J. (2015). A Large Sample Comparison of Grade Based Student Learning Outcomes in Online vs. Face-To-Face Courses. Olj, 19 (2), 25-32. doi:10.24059/olj.v19i2.454

Chuttur, M. Y. (2009). Overview of the Technology Acceptance Model: Origins, Developments and Future Directions. Sprouts: Working Pap. Inf. Syst. 9 (37), 9-37. Available at: http://sprouts.aisnet.org/9-37.

Davis, F. D. (1989). Perceived Usefulness, Perceived Ease of Use, and User Acceptance of Information Technology. MIS Q. 13 (3), 319-340. doi: $10.2307 / 249008$

Dewaele, J. M., Chen, X., Padilla, A. M., and Lake, J. (2019). The Flowering of Positive Psychology in Foreign Language Teaching and Acquisition Research. Front. Psychol. 10, 2128. doi:10.3389/fpsyg.2019.02128

Goodhue, D. L., and Thompson, R. L. (1995). Task-technology Fit and Individual Performance. MIS Q. 19 (2), 213-236. doi:10.2307/249689

Hakami, M. (2020). Using Nearpod as a Tool to Promote Active Learning in Higher Education in a BYOD Learning Environment. Jel 9 (1), 119-126. doi:10.5539/jel.v9n1p119

He, B. (2020). Research on the Autonomous Learning Mode of College English via the Internet in the Epidemic Situation. The 5th International Conference on Social Sciences and Economic Development (ICSSED 2020), Macau, China, March 6-8, 2020, 127-130. doi:10.2991/assehr.k.200331.027

Hillman, T., Rensfeldt, A. B., and Ivarsson, J. (2019). Brave New Platforms: a Possible Platform Future for Highly Decentralised Schooling. Learn. Media Tech. 45 (1), 7-16. doi:10.1080/17439884.2020.1683748 
Hodges, C., Moore, S., Lockee, B., Trust, T., and Bond, A. (2020). The Difference between Emergency Remote Teaching and Online Learning. Available at: https://er.educause.edu/articles/2020/3/the-difference-between-emergencyremote-teaching-and-online-learning.

Johnston, C., and Redlener, I. (2006). Critical Concepts for Children in Disasters Identified by Hands-On Professionals: Summary of Issues Demanding Solutions before the Next One. Pediatrics 117 (5), 458-460. doi:10.1542/peds.2006-0099W

Johnson, N., Veletsianos, G., and Seaman, J. (2020). U.S. Faculty and Administrators' Experiences and Approaches in the Early Weeks of the COVID-19 Pandemic. Olj 24 (2), 6-21. doi:10.24059/olj.v24i2.2285

Kebritchi, M., Lipschuetz, A., and Santiague, L. (2017). Issues and Challenges for Teaching Successful Online Courses in Higher Education: A Literature Review. J. Educ. Tech. Syst. 46 (1), 4-29. doi:10.1177/0047239516661713

Kite, J., Schlub, T. E., Zhang, Y., Choi, S., Craske, S., and Dickson, M. (2020). Exploring Lecturer and Student Perceptions and Use of a Learning Management System in a Postgraduate Public Health Environment. E-Learning and Digital Media 17 (3), 183-198. doi:10.1177/2042753020909217

Lonn, S., and Teasley, S. D. (2009). Saving Time or Innovating Practice: Investigating Perceptions and Uses of Learning Management Systems. Comput. Edu. 53 (3), 686-694. doi:10.1016/j.compedu.2009.04.008

Merriam, S. B. (2009). Qualitative Research: A Guide to Design and Implementation. San Francisco, CA: Jossey-Bass.

Moore, J. L., Dickson-Deane, C., and Galyen, K. (2011). E-Learning, Online Learning, and Distance Learning Environments: Are They the Same? Internet Higher Edu. 14 (2), 129-135. doi:10.1016/j.iheduc.2010.10.001

Mutambik, I. (2018). The Role of E-Learning in Studying English as a Foreign Language in Saudi Arabia: Students' and Teachers' Perspectives. Elt 11 (5), 74-83. doi:10.5539/elt.v11n5p74

Oyaid, A., and Alshaya, H. (2019). Saudi University Students Views, Perceptions, and Future Intentions towards E-Books. Malaysian Online J. Educ. Tech. 7 (1), 69-75. doi:10.17220/mojet.2019.01.005

Sharma, V. (2019). Saudi Students' Perspective on Social media Usage to Promote EFL Learning. Int. J. Linguistics, Lit. Translation 2 (1), 129-139. doi:10.32996/ ijllt.2019.2.1.17

Shih, Y.-Y., and Chen, C.-Y. (2013). The Study of Behavioral Intention for mobile Commerce: Via Integrated Model of TAM and TTF. Qual. Quant 47 (2), 1009-1020. doi:10.1007/s11135-011-9579-x

Swartz, B. C., Gachago, D., and Belford, C. (2018). To Care or Not to Care Reflections on the Ethics of Blended Learning in Times of Disruption. Sajhe 32 (6), 49-64. doi:10.20853/32-6-2659
Watermeyer, R., Crick, T., Knight, C., and Goodall, J. (2020). COVID-19 and Digital Disruption in UK Universities: Afflictions and Affordances of Emergency Online Migration. High Educ. (Dordr) 81 (4), 1-19. doi:10.1007/ s10734-020-00561-y

Williamson, B., Eynon, R., and Potter, J. (2020). Pandemic Politics, Pedagogies and Practices: Digital Technologies and Distance Education during the Coronavirus Emergency. Learn. Media Tech. 45 (2), 107-114. doi:10.1080/ 17439884.2020.1761641

$\mathrm{Wu}, \mathrm{B}$., and Chen, X. (2017). Continuance Intention to Use MOOCs: Integrating the Technology Acceptance Model (TAM) and Task Technology Fit (TTF) Model. Comput. Hum. Behav. 67, 221-232. doi:10.1016/j.chb.2016.10.028

Yuan, J., and Kim, C. (2014). Guidelines for Facilitating the Development of Learning Communities in Online Courses. J. Comp. Assist. Learn. 30 (3), 220-232. doi:10.1111/jcal.12042

Yuen, A. H. K., Deng, L., Fox, R., and Tavares, N. J. (2009). Engaging Students with Online Discussion in a Blended Learning Context: Issues and Implications. Proceedings of Second International Conference, Hybrid Learning and Education, Macau, China, August 25-27, 2009, 150-162. doi:10.1007/978-3642-03697-2_15

Zanjani, N., Edwards, S. L., Nykvist, S., and Geva, S. (2016). LMS Acceptance: The Instructor Role. Asia-pacific Edu Res. 25 (4), 519-526. doi:10.1007/s40299-0160277-2

Conflict of Interest: The author declares that the research was conducted in the absence of any commercial or financial relationships that could be construed as a potential conflict of interest.

Publisher's Note: All claims expressed in this article are solely those of the authors and do not necessarily represent those of their affiliated organizations, or those of the publisher, the editors and the reviewers. Any product that may be evaluated in this article, or claim that may be made by its manufacturer, is not guaranteed or endorsed by the publisher.

Copyright (c) 2021 Al Shlowiy. This is an open-access article distributed under the terms of the Creative Commons Attribution License (CC BY). The use, distribution or reproduction in other forums is permitted, provided the original author(s) and the copyright owner(s) are credited and that the original publication in this journal is cited, in accordance with accepted academic practice. No use, distribution or reproduction is permitted which does not comply with these terms. 